\title{
Correction to: Interactive granular computing
}

\author{
Andrzej Skowron ${ }^{1,2} \cdot$ Andrzej Jankowski $^{3} \cdot$ Soma Dutta ${ }^{1,4}$
}

Published online: 10 November 2018

(c) Springer Nature Switzerland AG 2018

\section{Correction to: Granul. Comput. (2016) 1:95-113 https://doi.org/10.1007/s41066-015-0002-1}

In the published article one of the grants is cancelled. The correct Acknowledgements section should read as:

Acknowledgements This work by Andrzej Skowron and Andrzej Jankowski was partially supported by the Polish National Science Centre (NCN) Grants DEC-2011/01/D/ ST6/06981, DEC-2012/05/B/ST6/03215, as well as by the Polish National Centre for Research and Development (NCBiR) under the Grant O ROB/0010/03/001. Soma Dutta was supported by the ERCIM postdoc fellowship.

Publisher's Note Springer Nature remains neutral with regard to jurisdictional claims in published maps and institutional affiliations.

The original article can be found online at https://doi.org/10.1007/ s41066-015-0002-1.

Andrzej Skowron

skowron@mimuw.edu.pl

Andrzej Jankowski

andrzej.adgam@gmail.com

Soma Dutta

somadutta9@gmail.com

1 Institute of Mathematics, Warsaw University, Banacha 2, 02-097 Warsaw, Poland

2 Systems Research Institute, Polish Academy of Sciences, Newelska 6, 01-447 Warsaw, Poland

3 The Dziubanski Foundation of Knowledge Technology, Nowogrodzka 31, 00-511 Warsaw, Poland

4 Vistula University, Stoklosy 3, 02-787 Warsaw, Poland 